\title{
ERRATUM
}

\section{Yoshihiko Fujita (1932-2005): A pioneer of photoregulation in cyanobacteria}

\author{
Akio Murakami · Mamoru Mimuro \\ (C) Springer Science+Business Media B.V. 2006 \\ Photosynthesis Research
}

DOI 10.1007/s11120-005-9029-5

Springer regrets that due to problems in the flow system of the proofs of this manuscript, the following corrections did not appear in the published article:

Third page of the article:

Left column, first paragraph, second line, the word sak should be saké.

The online version of the original article can be found at http:// dx.doi.org/10.1007/s11120-005-9029-5

\footnotetext{
A. Murakami $(\square)$

Kobe University Research Center for Inland Seas, Iwaya

2746, Awaji, Hyogo 656-2401, Japan

e-mail: akiomura@kobe-u.ac.jp

M. Mimuro

Hall of Global Environmental Research, Kyoto University,

Yoshida-Honmachi, Sakyoku, Kyoto 606-8501, Japan
} 